\title{
Diagnosis of the Forcing and Structure of the Coastal Jet near Cape Mendocino Using In Situ Observations and Numerical Simulations
}

\author{
David A. Rahn and Thomas R. Parish \\ Department of Atmospheric Science, University of Wyoming, Laramie, Wyoming
}

(Manuscript received 6 June 2006, in final form 13 November 2006)

\begin{abstract}
Several flights were conducted by the University of Wyoming King Air near Cape Mendocino, California, during June 2004 to examine finescale features of the coastal low-level jet (CJ) that frequently forms during summer over the ocean off the West Coast of the United States. The primary goal of these flights was to measure the horizontal pressure gradient force (PGF) and hence to determine the forcing of the CJ directly. By flying a series of redundant legs on an isobaric surface, heights of the pressure surface can be obtained from radar altimeter measurements and refined position estimates from an onboard global positioning system receiver. The slope of the isobaric surface height is proportional to the PGF. Results are shown for the 22 June 2004 case study conducted to the south of Cape Mendocino. The forcing of a CJ under weak synoptic forcing and the role of the elevated terrain near Cape Mendocino are explored. Ten isobaric legs approximately $70 \mathrm{~km}$ in length and directed east-west were conducted near the level of the maximum CJ wind speed. The vertical structure of the CJ was obtained from sawtooth legs conducted along an east-west flight leg. Numerical simulations have been performed for this case using the fifth-generation Pennsylvania State University-National Center for Atmospheric Research Mesoscale Model (MM5) for comparison with in situ measurements. Model simulations show pressure perturbations in the vicinity of the cape as the northerly winds associated with the CJ interact with the coastal topography. Close agreement is found between in situ measurements and MM5 analyses of the various state parameters and the PGF along the east-west flight track in the lee of Cape Mendocino. Strong variation in the PGF is observed along the flight path. Large ageostrophic accelerations are present in response to the adjustment of the CJ with Cape Mendocino, reflecting the force imbalance between the observed PGF and Coriolis force.
\end{abstract}

\section{Introduction}

A northerly low-level jet frequently forms off the California coast during late spring and summer. This coastal jet $(\mathrm{CJ})$ can be relatively strong, with a maximum wind speed often over $25 \mathrm{~m} \mathrm{~s}^{-1}$ (e.g., Beardsley et al. 1987; Zemba and Friehe 1987; Rogers et al. 1998; Pomeroy and Parish 2001), and it is found near the top of the marine atmospheric boundary layer (MABL; Bridger et al. 1993). The location and extent of the CJ can be variable depending on the synoptic conditions and the topographic features of the nearby coast (e.g., Winant et al. 1988; Burk and Thompson 1996; Rogers et al. 1998; Parish 2000). During summer, the Pacific Ocean high pressure center strengthens and dominates

Corresponding author address: Thomas R. Parish, Department of Atmospheric Science, University of Wyoming, Laramie, WY 82071.

E-mail: parish@uwyo.edu the low-level wind regime over the North Pacific. Subsidence from the Pacific high strongly caps an MABL that is shallow near the coast and deepens offshore (Dorman et al. 2000). The Pacific high and a thermal low over the continent set up a horizontal pressure distribution that supports a northerly surface wind along the West Coast. The CJ is influenced by the local coastal topography, as discussed by a number of authors such as Burk and Thompson (1996), Tjernström and Grisogono (2000), Ström et al. (2001), Edwards et al. (2001), and Pomeroy and Parish (2001).

This CJ phenomenon has been documented and examined through both numerical simulations (Chao 1985; Burk and Thompson 1996; Tjernström 1999; Tjernström and Grisogono 2000) and in situ measurements (Beardsley et al. 1987; Zemba and Friehe 1987; Rogers et al. 1998; Parish 2000; Ström et al. 2001; Edwards et al. 2001). As noted by Ström et al. (2001), documentation of the environment off the California coast and attendant MABL dynamics has been limited

DOI: 10.1175/JAM2546.1 


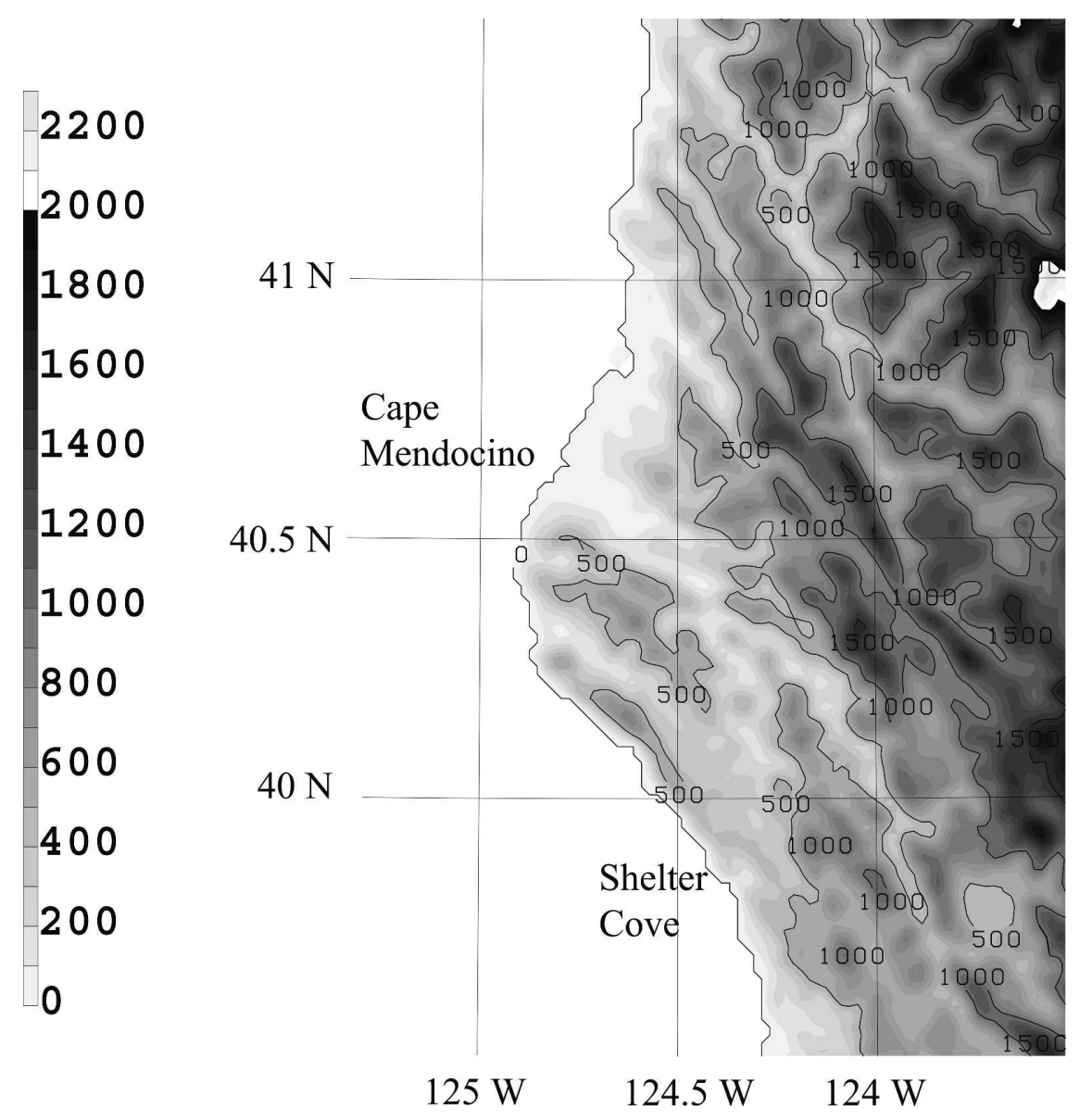

FIG. 1. Topographic map of the area in the vicinity of Cape Mendocino with significant geographic locations labeled. Contours of terrain are every $500 \mathrm{~m}$ and are shaded every $200 \mathrm{~m}$.

to just a few cases. Here we report on the dynamics of the $\mathrm{CJ}$ based on instrumented aircraft flights during a case study in June of 2004 in the vicinity of Cape Mendocino, California. Numerical simulations provide a three-dimensional context for aircraft observations at a particular point in space and time and are used here as a means to compare with the observational data on the structure and forcing of the CJ.

Emphasis for the airborne study is placed on the direct measurement of the horizontal pressure gradient force (PGF) near the top of the MABL by the University of Wyoming King Air (UWKA) research aircraft. The fundamental idea behind measuring the PGF is to fly an instrumented aircraft along an isobaric surface. Heights are recorded from radar altimeter measurements or can be inferred from accurate position estimates using a global positioning system (GPS) receiver on the UWKA. The slope of the isobaric surface along the flight path can be determined, and therefore the PGF can be computed. Two difficulties must be overcome to achieve an accurate measurement of the PGF.
First, the slope of an isobaric surface is relatively small. For example, a $10 \mathrm{~m} \mathrm{~s}^{-1}$ geostrophic wind at $43^{\circ} \mathrm{N}$ corresponds to an isobaric slope of only about $10^{-4}$, which means that there is only a $1-\mathrm{m}$ change in height over $10 \mathrm{~km}$. Even small errors in the measurement of the isobaric surface height have an adverse impact on the PGF calculation. The second issue concerns the timespace transformation. As the aircraft moves along an isobaric surface, isallobaric tendencies may be present. If the height of the isobaric surface rises or falls in response to local pressure changes, derived slopes of the isobaric surface contain a spurious signal (Parish et al. 1988) that must be removed. Because there are limited surface observations over the ocean, correction is nearly impossible without redundant flight legs.

Two major topographical features of the California coast in the region of this study - the steep coastal mountain range and the Cape Mendocino headlandare the prominent features of interest (Fig. 1). The coastal terrain provides a nearly continuous barrier along the West Coast that is typically $1000 \mathrm{~m}$ in height 


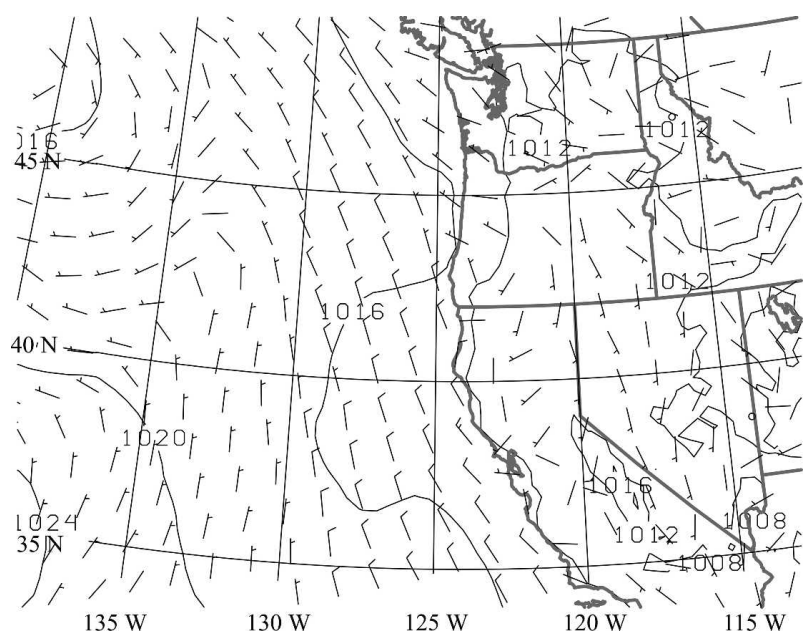

FIG. 2. Eta analysis from the 212 grid on 2100 UTC 22 Jun 2004 showing sea level pressures $(\mathrm{hPa})$ and wind barbs $\left(\mathrm{m} \mathrm{s}^{-1}\right)$.

and above the level of the MABL, thereby serving as an effective barrier to low-level flows. Cape Mendocino protrudes approximately $40-60 \mathrm{~km}$ into the Pacific Ocean, with a peak that rises to just over $800 \mathrm{~m}$ above the neighboring ocean, and disrupts the northerly flow along the coast. The strong MABL along the coast of California becomes modulated by the terrain of the California coast, and the dynamics of the low-level flows are significantly different north and south of Cape Mendocino.

Synoptic conditions on 22 June 2004 from the Eta Model analysis are typical of the summertime MABL. There is subsidence aloft resulting from convergence at upper levels associated with the Pacific high. In addition, cold-air advection is occurring at $700 \mathrm{hPa}$ over the region off the West Coast of the United States. Subsidence above the large cold pool over the ocean results in an inversion of $5^{\circ}-10^{\circ} \mathrm{C}$ that caps the MABL. At the surface, there is a broad area of high pressure over the Pacific Ocean with the largest surface pressure gradient near the shore, as shown in Fig. 2. Relative to that of previous studies such as Pomeroy and Parish (2001), the large-scale PGF is weak. A coastally trapped wind reversal moved northward along the California coast on 17 June, and the pressure field on 22 June was still adjusting back to a more normal state. Weak northerly winds associated with the Pacific high follow the coastline.

The purpose of this paper is to determine the dynamics responsible for the observed characteristics of the CJ based on the finescale UWKA measurements. The generally good agreement of the observations with results from a high-resolution numerical model for this particular case allows the dynamics to be viewed in a larger-scale context, providing some confidence in the ability of the model to simulate properly the atmospheric dynamics in the near-coastal region. The CJ is examined in detail for the flight of 22 June 2004. This particular case is chosen because the flight samples a well-developed CJ that forms in response to weak synoptic forcing; thus, the case is a good example of how the coastal topography affects the flow dynamics.

\section{Data sources}

\section{a. Observations}

The key measurement in understanding the dynamics of the CJ is the PGF. The flight strategy used is simply to fly a straight east-west track on an isobaric surface. The height of the aircraft above the ocean is monitored with small deviations of the aircraft autopilot off the isobaric surface being corrected by the hydrostatic equation. By directing the flight to be primarily orthogonal to the geostrophic wind, the largest component of the horizontal pressure gradient can be determined. Two main techniques are used to measure the height of an isobaric surface using an airborne platform. The first method requires radar altimetry (Shapiro and Kennedy 1982; Rodi and Parish 1988). In this technique, a radar altimeter is used to detect the height of the aircraft above the ground. Horizontal position estimates obtained from either GPS or other navigational aids can be used to infer the height of the underlying surface above some reference level such as sea level. Adding the radar altimeter height to the height of the underlying surface provides the height of the isobaric surface above some reference level. This "terrain registration" process has proven to be the weakness of the altimetry method over irregular terrain because even small discrepancies between actual surface heights and those inferred from digital maps can produce significant errors. In practice, the terrain slopes present over land are of opposite sign to the radar altimeter height; the isobaric height thus represents the sum of two large terms that are opposed to one another. This PGF-detection process is simplified when flying over the ocean if it is assumed that the underlying surface is uniform at sea level. Ocean surface topography variations were observed over the open ocean during certain flights of the June 2004 field campaign, which underscores inherent problems with altimetry-based methods to determine the PGF.

The second method employs GPS measurements to find the absolute height above a reference level (Parish et al. 2007). This method can be used globally regardless of the underlying topography. The accuracy is dependent on the configuration of the satellite constella- 
tion at the time of the measurement and the availability of a fixed GPS receiver nearby for differential postprocessing. The June 2004 flights were specifically conducted to assess the potential of GPS to provide measurements of the PGF. An Ashtech Z-Sensor GPS receiver is installed on the UWKA. It is a dual-channel receiver that is able to track and record the carrier phase on two GPS frequencies (labeled L1 and L2) in addition to the coarse/acquisition code broadcast on L1. Position data from the UWKA GPS is refined in a postprocessing mode using GPS data from fixed stations at precisely surveyed locations in the vicinity of the flight path.

For the California study, dual-frequency $1-\mathrm{Hz}$ GPS data were collected at a fixed site at the base hangar at Arcata, California; 5-s GPS data were also obtained from the National Geodetic Survey Continuously Operating Reference Station (CORS) at Cape Mendocino. Differential processing of the GPS data was then made using GrafNav/GrafNet software from Waypoint Consulting, Inc. Refined GPS position data presented here were obtained using both the base station at Arcata and the Cape Mendocino CORS site as the "master" GPS data, with the UWKA GPS data as the rover. Datasets described in this study typically had baselines shorter than $100 \mathrm{~km}$, which should provide an overall accuracy in the derived position of better than $0.5 \mathrm{~m}$ with dualfrequency, carrier-phase differential processing. Aircraft heights above sea level (orthometric) were computed with respect to "GEOID99." For the 22 June case, excellent agreement was found between PGF calculations using altimetry methods and the GPS technique. For brevity, only the GPS-derived heights and PGF will be shown.

\section{b. Numerical simulation}

Numerical simulation of the 22 June 2004 event was conducted using version 3.7 of the fifth-generation Pennsylvania State University-National Center for Atmospheric Research Mesoscale Model (MM5; Grell et al. 1994). The simulations conducted in this study consist of three domains centered over Cape Mendocino with grid spacings of 15,5 , and $1.67 \mathrm{~km}$ with grids of $121 \times 121,121 \times 121$, and $190 \times 163$, respectively. A schematic of the grids is shown in Fig. 3. The vertical grid consists of 35 sigma levels. Because the CJ occurs at a low level, the spacing of sigma levels is enhanced in the lower part of the domain to capture high-resolution details. There are 13 sigma levels between the surface and $900 \mathrm{hPa}$. For this simulation, the MRF boundary layer parameterization scheme was used.

Analysis grids from the Eta Model initialization at a $40-\mathrm{km}$ resolution were used to initialize the mother do-

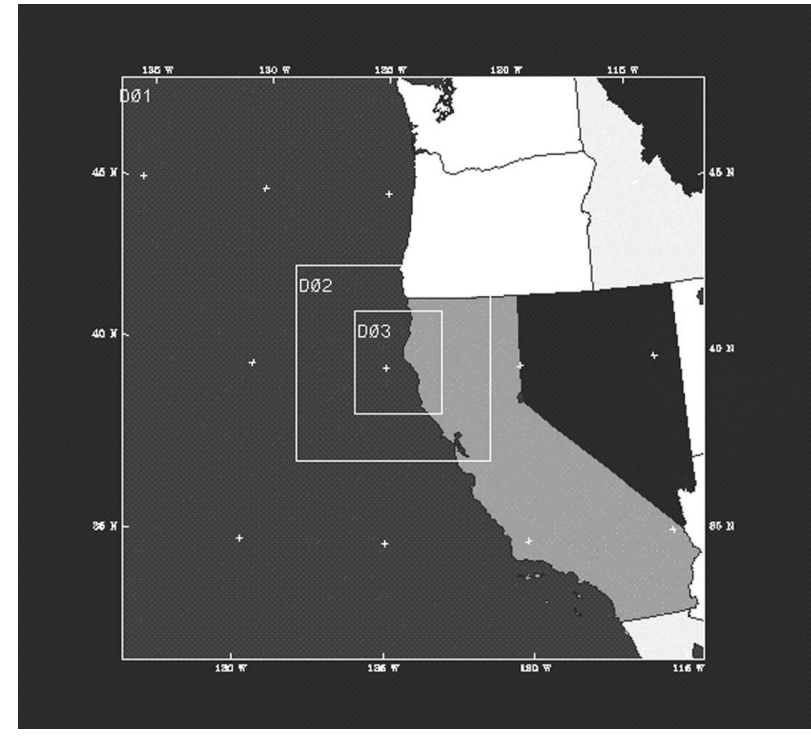

FIG. 3. Domains used in the MM5 simulation. An outer domain (D01) and two inner domains (D02 and D03) are represented by the boxes and correspond to a grid spacing of 15,5 , and $1.67 \mathrm{~km}$, respectively.

main's boundary conditions in MM5. Because there is a discrepancy between the resolution of the available Eta Model analysis and the desired resolution of the numerical simulation, a spinup time on the order of a few hours was necessary. For the 22 June 2004 case, MM5 was initialized from the 0000 UTC grids from 22 June. The flight was conducted from 1830 to 2300 UTC, and so the model output represents a forecast time of 18-24 h. The MM5 simulation agreed well with the observations but will not capture the sharp changes of the isobaric surface that the observations show. The wide grid spacing of the initial Eta Model grid and the initial interpolation of the analysis lead to some initial error, but the final flow field is not significantly different from that observed.

\section{Observations}

The primary area of measurement took place to the south of Cape Mendocino as shown in Fig. 4; this area was free from clouds. The flight strategy on 22 June 2004 consisted of 10 isobaric legs and a sawtooth profile leg. The first four legs along $40.1^{\circ} \mathrm{N}$ occurred from 1907 to $1958 \mathrm{UTC}$ between $124.7^{\circ}$ and $124.2^{\circ} \mathrm{W}$ at an average pressure level of $985.5 \mathrm{hPa}$, corresponding to a height of approximately $240 \mathrm{~m}$ above the ocean. The fifth leg is the sawtooth maneuver during which time the UWKA varied elevation between 70 and $700 \mathrm{~m}$ to measure the vertical structure of the MABL. The next four isobaric legs (legs 6-9) are also flown along $40.1^{\circ} \mathrm{N}$ but at a level 


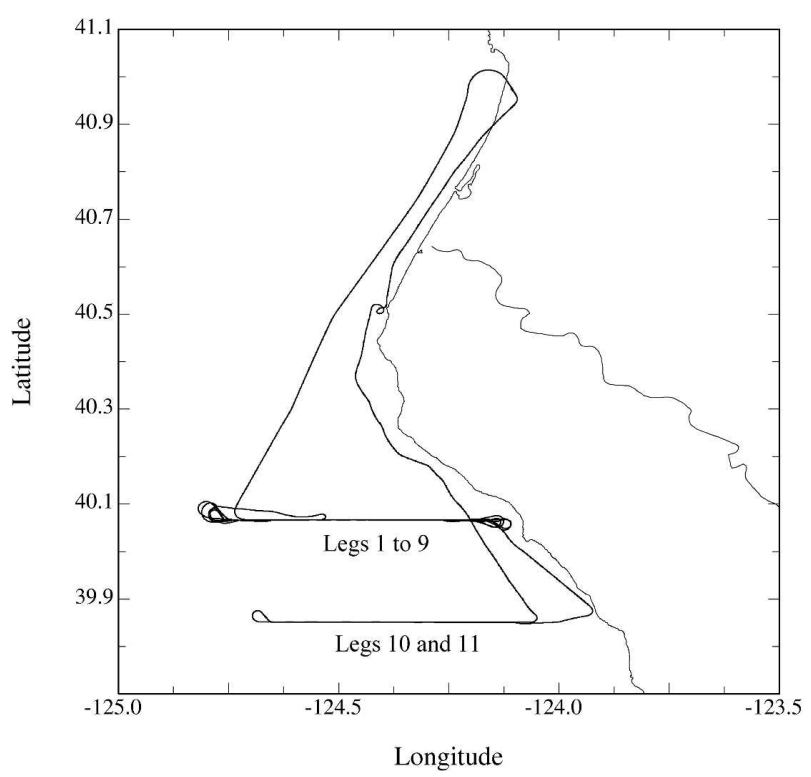

FIG. 4. Flight track on the afternoon of 22 Jun 2004.

of $996.7 \mathrm{hPa}$, approximately $130 \mathrm{~m}$ above the ocean, from 2016 to 2113 UTC. The last two legs (legs 10 and 11) were flown to the south of the previous legs along $39.8^{\circ} \mathrm{N}$ between $124.1^{\circ}$ and $124.66^{\circ} \mathrm{W}$ at an average level of $996.6 \mathrm{hPa}$ from 2125 to 2151 UTC. Redundant legs were used to alleviate the possible problem of pressure tendencies and transient finescale features and thus the time-to-space transformation issues.

Because these flight legs are directed in an east-west manner, the figures in this section indicate location by longitude only. For reference, the headland of Cape Mendocino is at about $124.35^{\circ} \mathrm{W}$. An important note is that these flight legs capture only the along-flight $x$ component of the PGF. This is by far the largest component of the PGF, but does not correspond to the total PGF at all points. Based on results from MM5, the northern legs (legs 1-9) are directed such that the flight path is nearly normal to the isobars. The orientation of the PGF for the two southern legs from MM5 suggests that the flight track differs from the pressure gradient by about $20^{\circ}$.

\section{a. Legs 1-4}

A composite of potential temperatures and wind components observed by the UWKA platform during the 986-hPa legs and corresponding winds as simulated by MM5 are shown in Figs. 5a,b. Inspection of the potential temperature traces suggests that the UWKA was in the MABL along the western half of the legs; the sharp increase in potential temperature during the easternmost portion is consistent with the collapse of the
MABL. The range in simulated temperatures (Fig. 5b) is larger, but the general structure is similar. MM5 simulations place the point of MABL collapse about 12 $\mathrm{km}$ to the east of what is observed. Observed wind components (Fig. 5c) are consistent with the temperature trends in Fig. 5a, with the strongest winds of $20 \mathrm{~m} \mathrm{~s}^{-1}$ observed to the south of the Cape Mendocino headland and a rapid decrease corresponding to the MABL collapse near Shelter Cove. The $x$ component of the wind increases steadily toward the east as the unbalanced flow accelerates down the isobaric surface. The wind profile is consistent with the simulated wind from MM5 (Fig. 5d).

Heights of the 986-hPa surface as derived from the differential GPS technique for the first four legs are illustrated in Fig. 6a. Significant variations are seen along the flight track, especially near the eastern end of the flight path where the MABL collapses near Shelter Cove, which also corresponds roughly to the longitude of the Cape Mendocino headland $\left(\sim 124.35^{\circ} \mathrm{W}\right)$. A second discontinuity in the $986-\mathrm{hPa}$ heights can be seen to the west where the aircraft goes below the inversion at the top of the MABL. All four legs show similar trends in the isobaric slopes except for the far eastern end of the legs. This result suggests little pressure change was occurring during the course of the flight and only small isallobaric tendencies are present within the MABL, which is consistent with MM5 results shown later. Noticeable height variations are seen at the far eastern end of the legs and are interpreted as being the result of a higher amount of turbulence, owing to the collapse of the MABL and the generally more turbulent motions associated with this region.

Given the three distinct trends in the isobaric surface, each will be considered when determining geostrophic winds. The separation location of these three regions is based primarily on the discontinuities in the isobaric surface, and potential temperature is also used to aid in the determination of the regions for the model output because the isobaric surface is smoother, especially in the western region. The central region in the model is about $8 \mathrm{~km}$ wider. The locations of these three regions are marked for reference as vertical lines. Isobaric slopes indicate a pronounced PGF over nearly the entire leg. Averaged over the entire leg, the PGF is equivalent to a $44 \mathrm{~m} \mathrm{~s}^{-1}$ equivalent geostrophic wind. The strongest forcing is seen in the middle section that best reflects the influence of the Cape Mendocino topography, with subsidence owing to mass divergence and effects such as expansion-fan dynamics and flow over the cape. Here the PGF is equivalent to a geostrophic wind speed of $67 \mathrm{~m} \mathrm{~s}^{-1}$. To the west, isobaric slopes are still large, equivalent to a geostrophic wind 

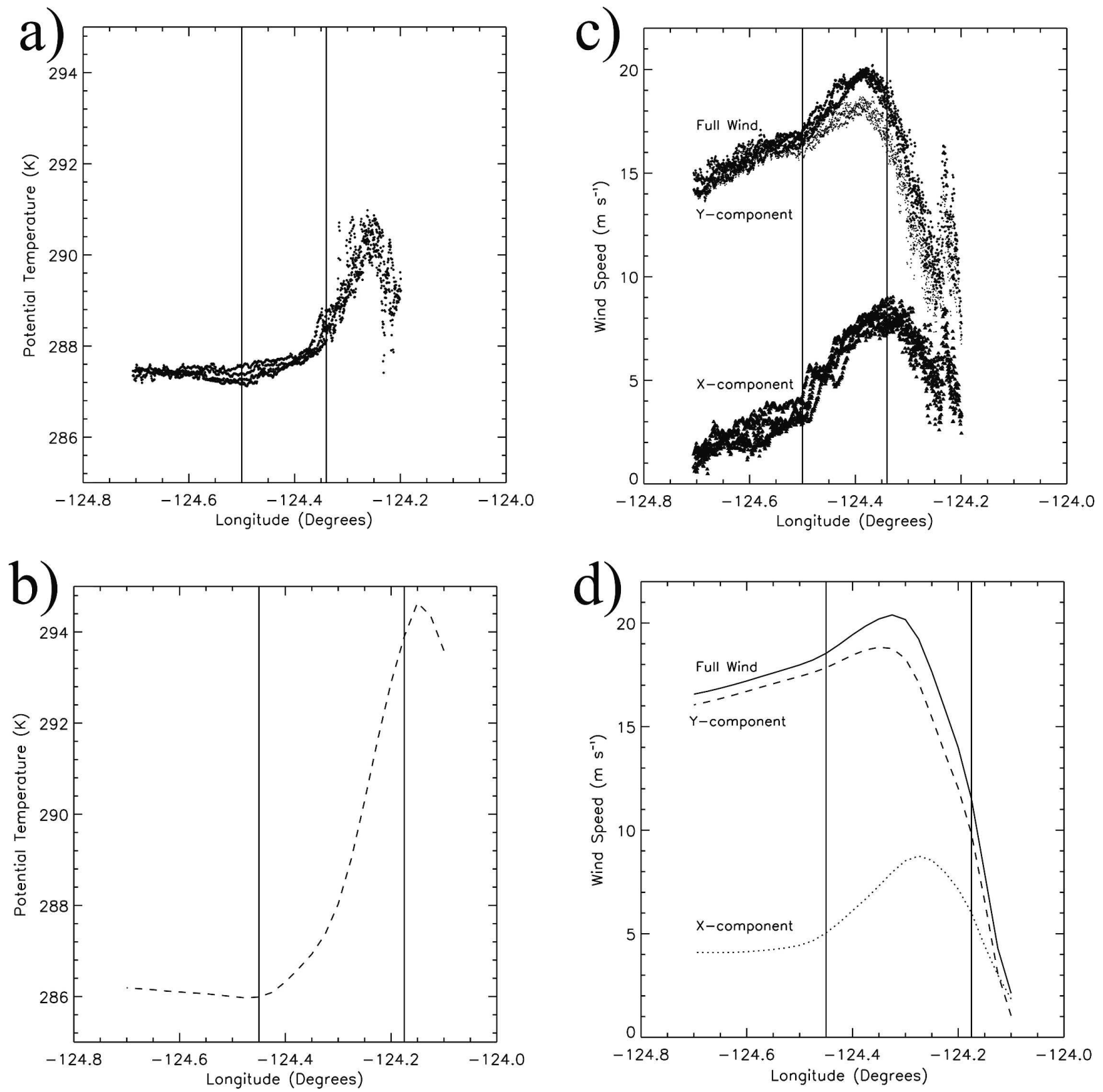

FIG. 5. Potential temperature measurements (K) from (a) the combined first four legs and (b) simulated by MM5 valid at 1930 UTC. Wind speed measurements $\left(\mathrm{m} \mathrm{s}^{-1}\right)$, with the $x$ component, $y$ component, and total wind speed depicted separately, (c) for the combined first four legs and (d) as simulated by MM5 valid at 1930 UTC. The three separate regions are separated with vertical lines.

speed of $33 \mathrm{~m} \mathrm{~s}^{-1}$. As the UWKA passes through the MABL, the PGF weakens dramatically (equivalent geostrophic wind of $11 \mathrm{~m} \mathrm{~s}^{-1}$ ) and changes sign.

Comparison of the isobaric slopes measured by the UWKA can be made with concurrent isobaric heights inferred from MM5. Figure 6b depicts the $986-\mathrm{hPa}$ isobaric heights from MM5 simulations. The model shows the same general features, including the enhanced slope near the center and the sign change through the
MABL. It is impressive that the MM5 simulation suggests the same three regions of isobaric slopes that have been observed. The discontinuity associated with the Cape Mendocino headland is less well defined than that suggested by observations but is still apparent, most notably by the beginning of the rapid increase in potential temperature. The geostrophic wind for the western portion is $34 \mathrm{~m} \mathrm{~s}^{-1}$ and for the center portion is $70 \mathrm{~m} \mathrm{~s}^{-1}$, a difference from the observations of 1 and 

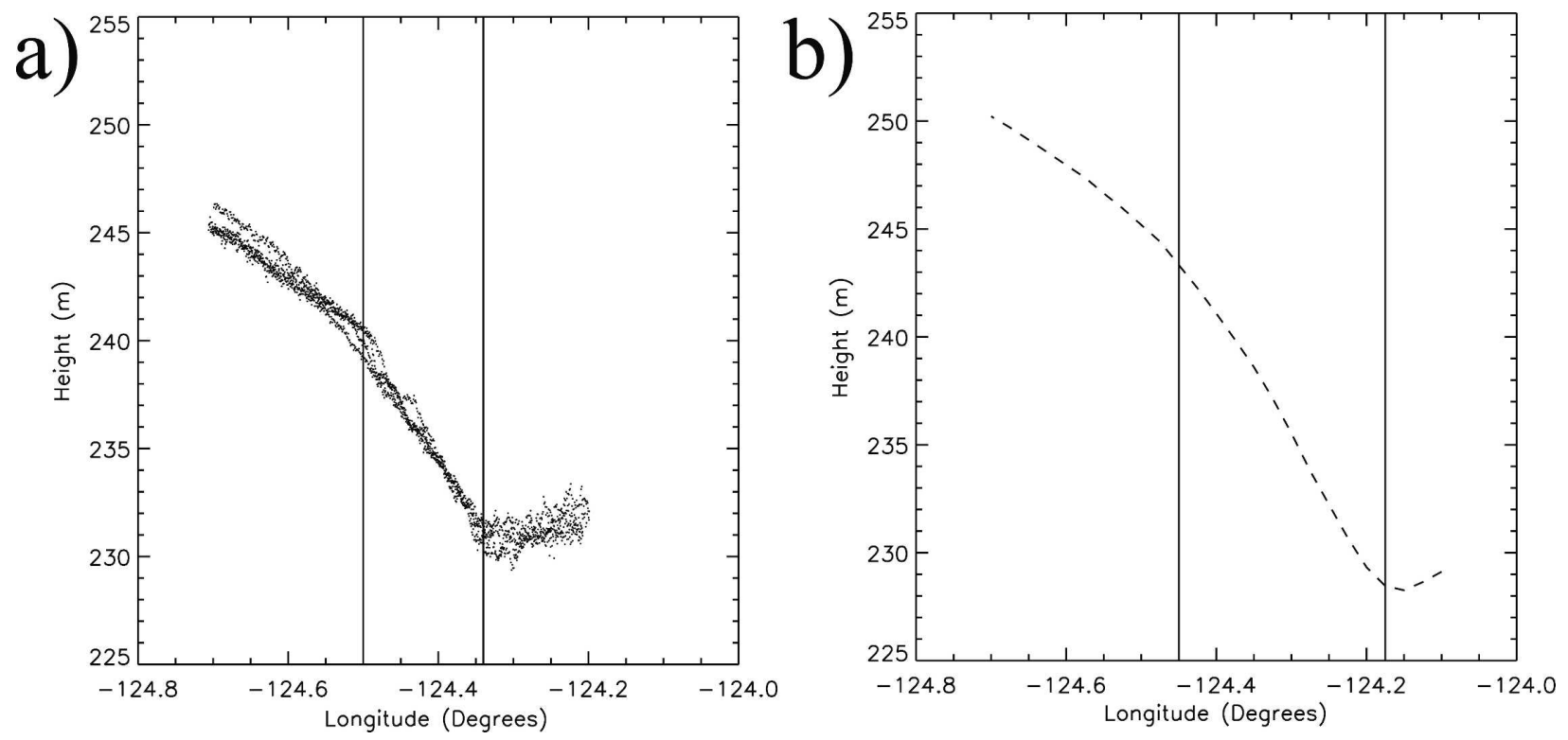

FIG. 6. (a) Scatterplot of the along-flight, corrected height measurements $(\mathrm{m})$ of the 985.5-hPa isobaric surface for the combined first four legs, and (b) the $985.5-\mathrm{hPa}$ isobaric surface simulated by MM5 valid at 1930 UTC. The three separate regions are separated with vertical lines.

$3 \mathrm{~m} \mathrm{~s}^{-1}$, respectively. The close agreement in geostrophic wind calculations provides confirmation of the ability of MM5 to simulate the pressure gradient south of the cape. Comparison between the actual winds with calculated geostrophic winds shows large ageostrophic components to the south of Cape Mendocino. The ageostrophic nature is also similar to that observed by Ström et al. (2001) for their strong-CJ cases in June of 1996.

\section{b. Legs 6-9}

For legs 6-9, the horizontal location is the same as that for legs 1-4, but the pressure level flown is $997 \mathrm{hPa}$, which is about $10 \mathrm{hPa}$ higher and corresponds to a mean height that is about $100 \mathrm{~m}$ lower. Heights of the 997-hPa isobaric surface shown in Fig. 7 are similar to those seen in Fig. 6. The three main regions described
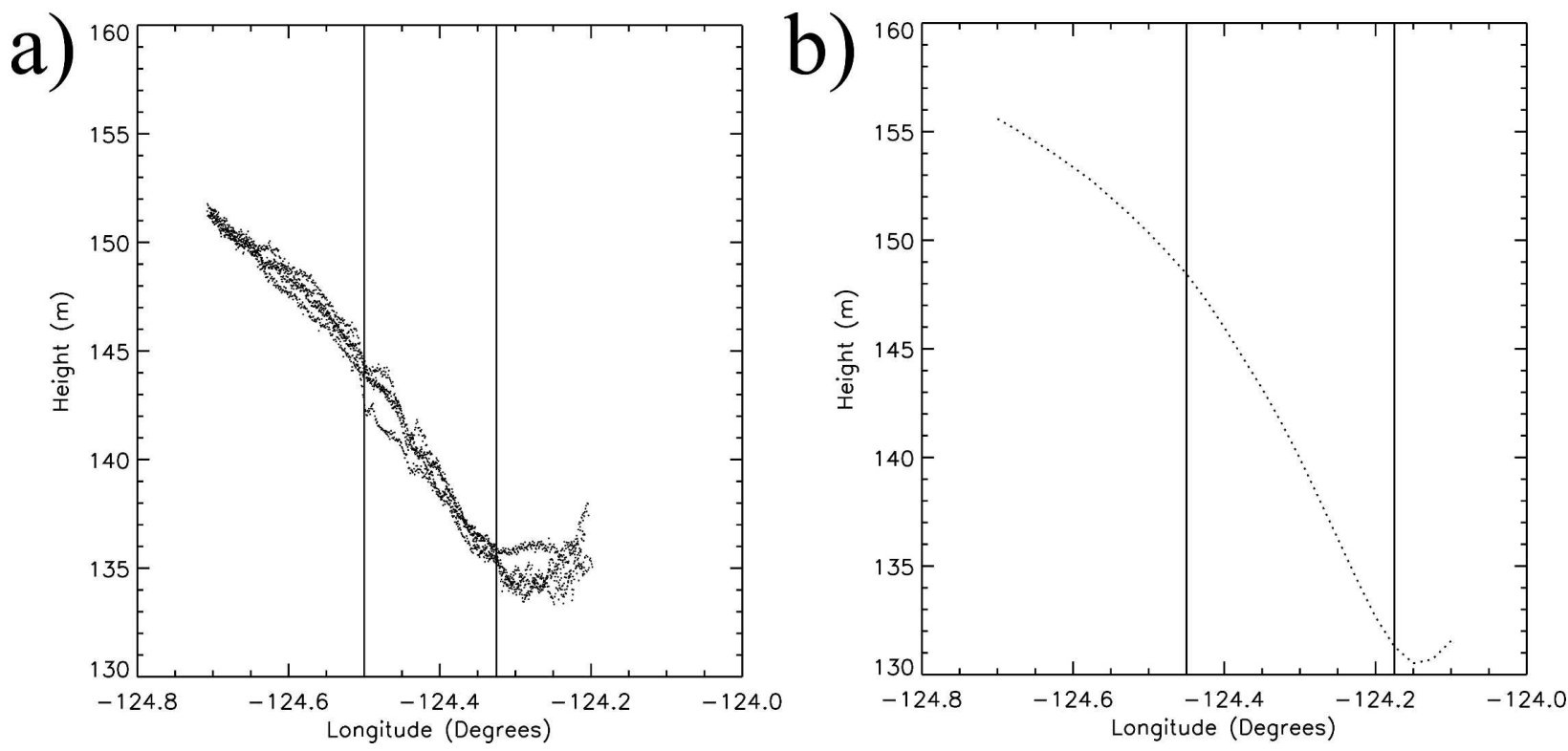

FIG. 7. (a) Scatterplot of the corrected height measurements $(\mathrm{m})$ of the $996.7-\mathrm{hPa}$ isobaric surface for the combined legs 6-9, and (b) the $996.7-\mathrm{hPa}$ isobaric surface simulated by MM5 valid at 2100 UTC. The three separate regions are separated with vertical lines. 

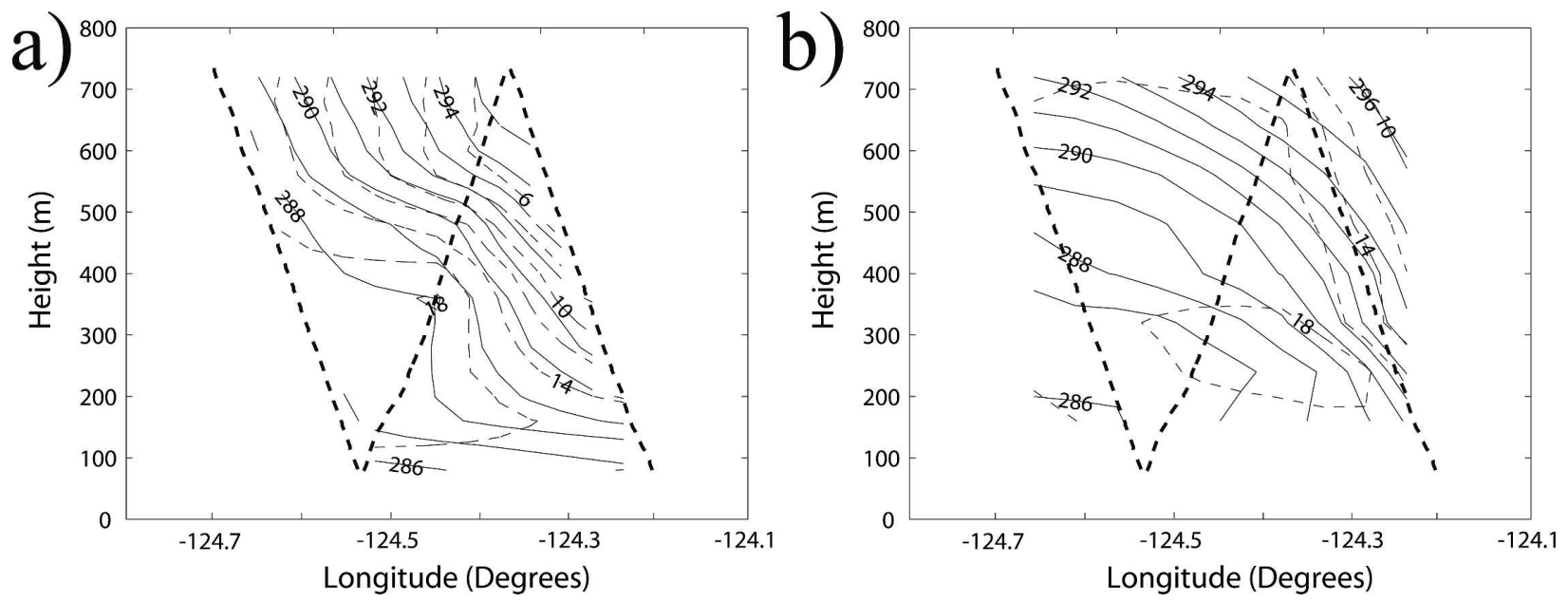

FIG. 8. Sawtooth pattern (a) as observed on the fifth leg (thick dashed line), with the contoured observations of potential temperature (solid line, $\mathrm{K}$ ) and wind speed (thin dashed line, $\mathrm{m} \mathrm{s}^{-1}$ ), and (b) as simulated by MM5 valid at 2100 UTC.

above can still be identified, although not as distinctly as in Fig. 6. For consistency, geostrophic wind calculations have been made for the same regions as shown in Fig. 6. Starting with the westernmost region, the geostrophic wind speed is $40 \mathrm{~m} \mathrm{~s}^{-1}$, which is slightly greater than that of the same region above. The geostrophic wind speed of the central region is still strong at $63 \mathrm{~m} \mathrm{~s}^{-1}$. The transition between the central and eastern portion is also a strong one, with some significant turbulence again in the eastern portion. The position of the discontinuity, the structure of the surface, and the high variability of the observations in this region differ greatly among legs, with no uniform trend. This suggests that small-scale disturbances are significantly affecting the region with smaller time scales than the time between measurements. The geostrophic wind speed here is $9 \mathrm{~m} \mathrm{~s}^{-1}$ from the south. The model again shows the general trend (Fig. 7b), with a geostrophic wind of $35 \mathrm{~m} \mathrm{~s}^{-1}$ in the west, but shows an enhanced slope in the center with a geostrophic wind of $79 \mathrm{~m} \mathrm{~s}^{-1}$. Ageostrophic wind components inferred from the UWKA data are approximately 2 times the magnitude of the actual wind, again reflecting the large force imbalance to the south of Cape Mendocino and consistent with MM5 simulations.

\section{c. Leg 5}

The fifth leg is the sawtooth leg from which the vertical structure of the $\mathrm{CJ}$ can be determined. Contours of potential temperature and wind speed from the sawtooth profile are shown in Fig. 8a. Relative to the winds from MM5 (Fig. 8b), the in situ measurements are somewhat weaker, but the general pattern is consistent.
A stable MABL with a sloping top is present, with a 7-K difference in potential temperature across the inversion. A deeper well-mixed layer is below the top portion of the MABL and contains the entire western descending portion. There is a jet maximum in excess of $18 \mathrm{~m} \mathrm{~s}^{-1}$ just below the top of the MABL. Wind speeds decrease rapidly to the east, which again depicts the collapse of the MBL and dramatic transition between the MABL and the free troposphere.

\section{d. Legs 10-11}

Legs 10-11 are conducted some $25 \mathrm{~km}$ to the south of the previous legs. It is expected from Pomeroy and Parish (2001) and MM5 simulations that the PGF should relax downstream from Cape Mendocino. Heights of the 997-hPa surface for the last two legs (legs 10-11) are consistent with this expectation, as shown in Fig. 9. Two distinct trends are seen in the isobaric heights, with the transition point downstream of the Cape Mendocino headland. The discontinuity seen toward the eastern end of legs 1-4 and 6-9 was not seen in these last two legs because the flight path did not reach the point of MABL collapse. The most striking feature is the prominent wave that exists near the center of these last two legs. The second feature is the more linear nature of the isobaric surface to the east and west of this center feature. In leg 11 there is some clear nonlinearity in the far eastern region. The general slopes for these two redundant legs tend to agree reasonably well. In the western region, the geostrophic wind speed is $36 \mathrm{~m} \mathrm{~s}^{-1}$, and the eastern region has a geostrophic wind speed of $18 \mathrm{~m} \mathrm{~s}^{-1}$. Figure $9 \mathrm{~b}$ illustrates the $997-\mathrm{hPa}$ isobaric surface heights from MM5. 

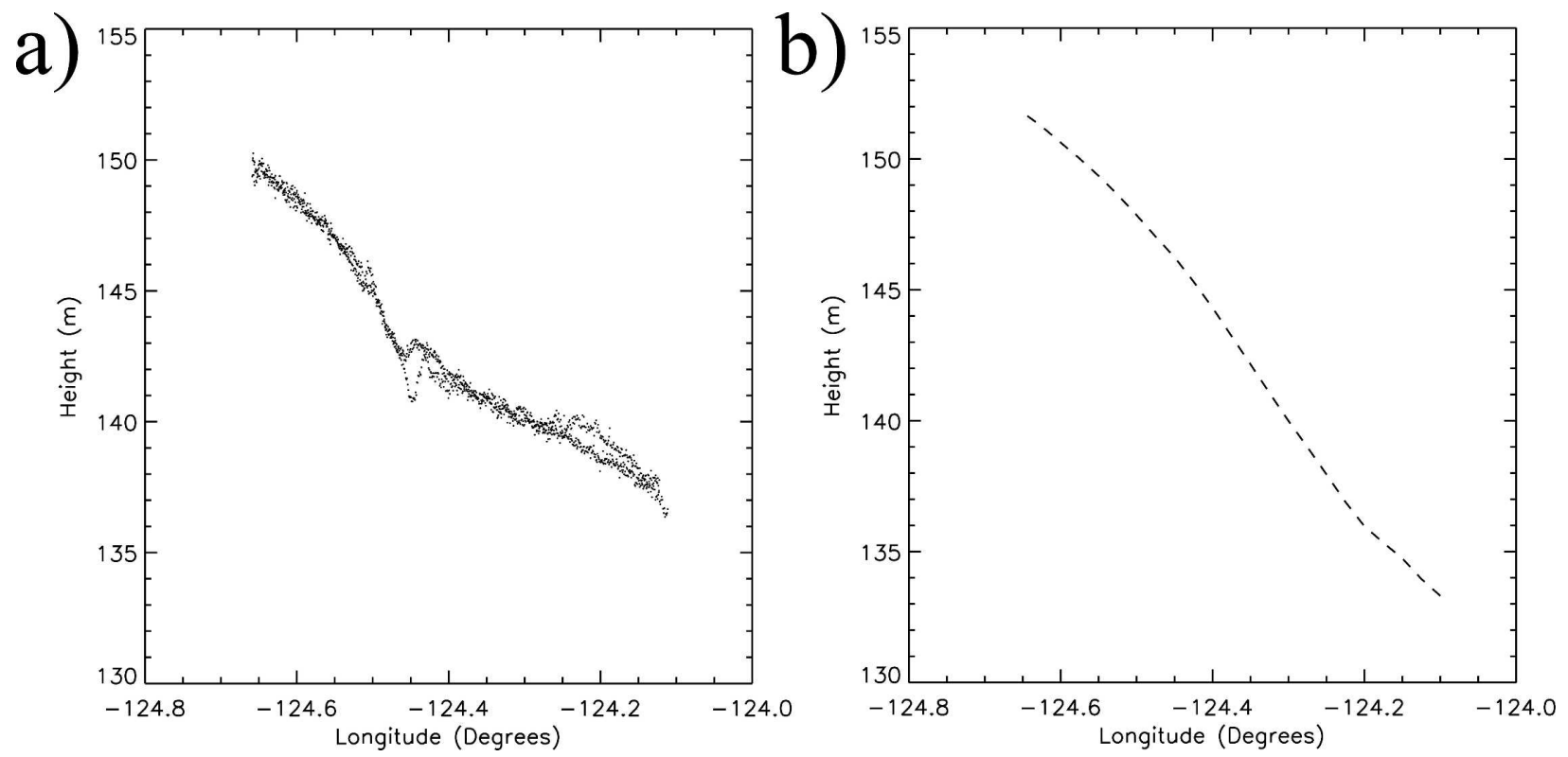

FIG. 9. (a) Scatterplot of the along-flight corrected height measurements $(\mathrm{m})$ of the $996.7-\mathrm{hPa}$ isobaric surface for the combined last two legs, and (b) the 996.7-hPa isobaric surface simulated by MM5, valid at 2130 UTC.

There is good agreement in the overall isobaric height trends between MM5 and UWKA measurements, although isobaric slopes are larger in MM5 simulation. Observations suggest a geostrophic wind over the entire leg of $28 \mathrm{~m} \mathrm{~s}^{-1}$, which is somewhat less than the $44 \mathrm{~m} \mathrm{~s}^{-1}$ in by MM5 simulation.

Figure 10a shows the observed wind that generally increases toward the east, but, unlike the leg to the north, it does not have a major, distinct peak. This is due to the fact that the southern leg is contained entirely within the MABL. The $x$ component is much stronger here than that seen to the north, consistent with an ageostrophic acceleration down the steep slope to the east. The geostrophic wind measured by the air-
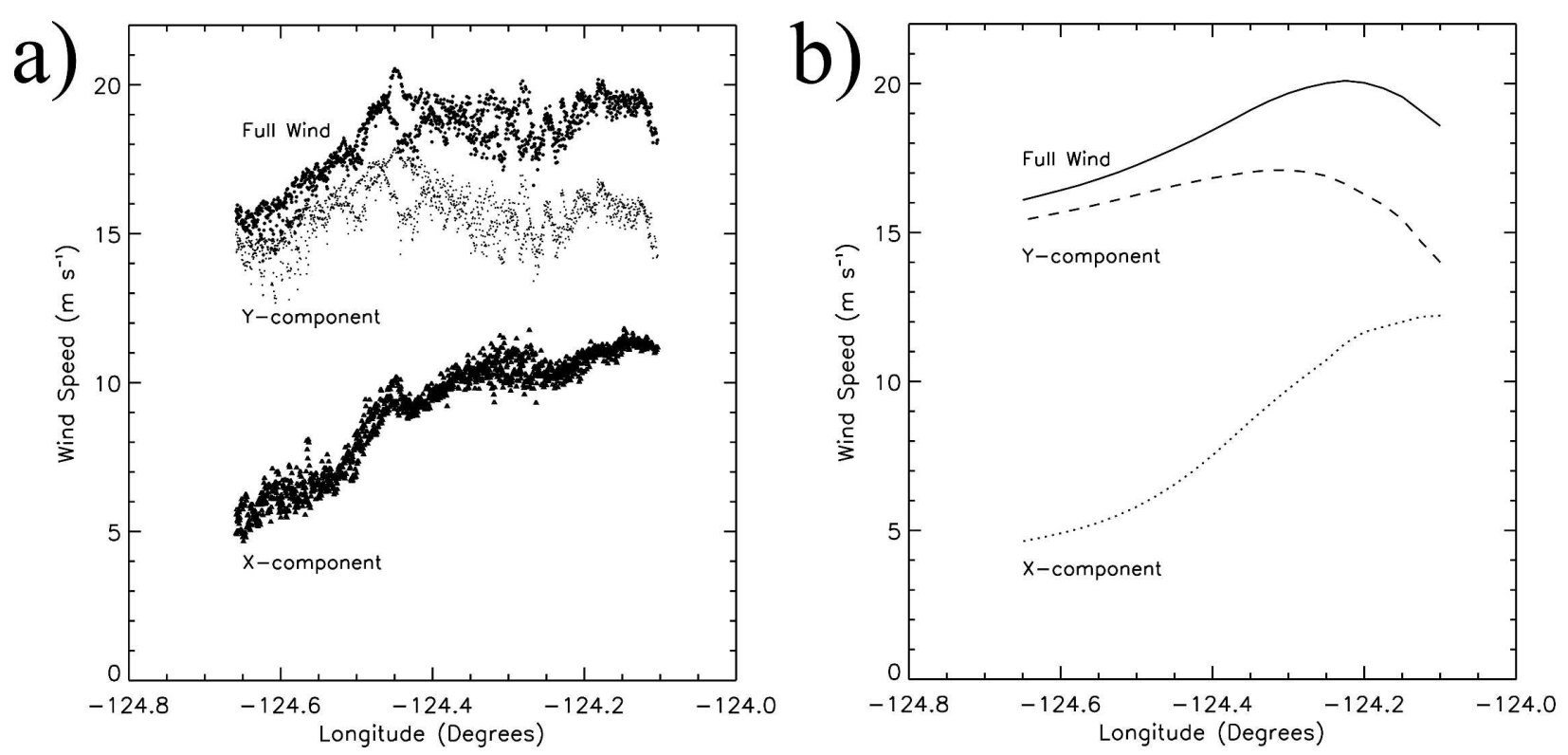

FIG. 10. Wind speed measurements $\left(\mathrm{m} \mathrm{s}^{-1}\right)$, with the $x$ component, $y$ component, and total wind speed depicted separately, (a) as indicated from the combined last two legs and (b) as simulated by MM5, valid at 2130 UTC. 


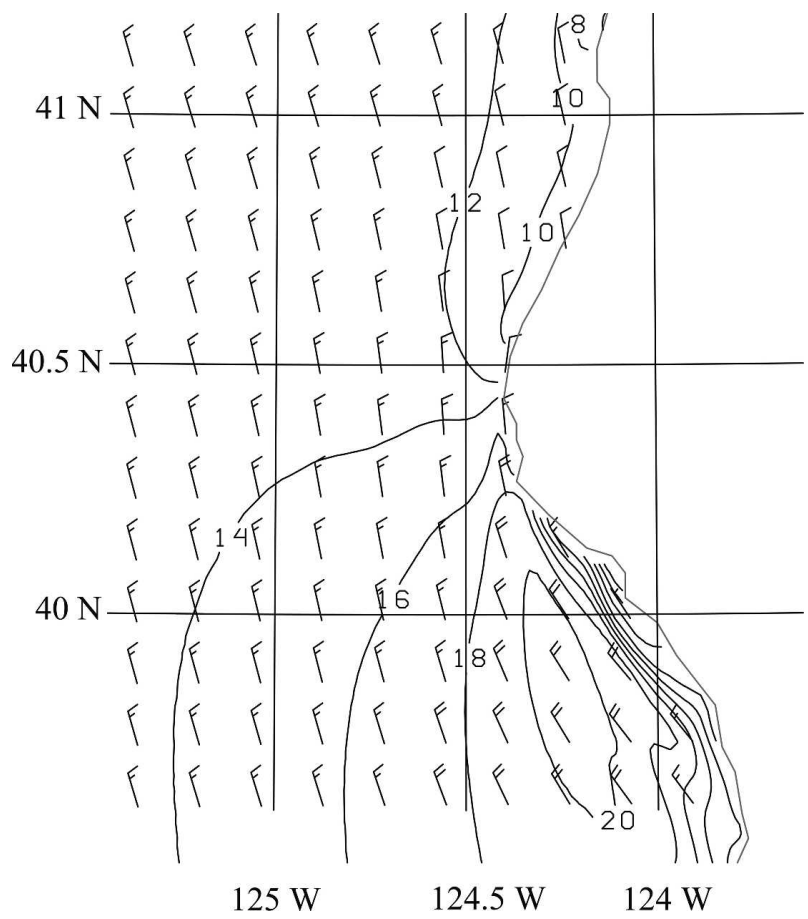

FIG. 11. Wind speed $\left(\mathrm{m} \mathrm{s}^{-1}\right)$ and wind barbs $\left(\mathrm{m} \mathrm{s}^{-1}\right)$ on the 990-hPa surface from the MM5 21-h forecast valid at 2100 UTC 22 Jun 2004.

craft is $36 \mathrm{~m} \mathrm{~s}^{-1}$ in the western region and $18 \mathrm{~m} \mathrm{~s}^{-1}$ in the eastern section, but the actual wind ranges between 15 and $20 \mathrm{~m} \mathrm{~s}^{-1}$ over the entire leg. Ageostrophic components of the wind along these legs are thus less than that observed to the north but are still comparable in magnitude to the actual wind. The $y$ component of the wind is relatively constant throughout the legs, with speeds somewhat less to the west, and the $x$ component steadily decreases to the west. MM5 shows similar trends in the speeds of the wind components. There is evidence in the UWKA wind measurements of the wave present in the isobaric surface near the central part of the leg. A small peak in the $x$ component appears at the same location of the wave, suggesting that the wave is propagating to the east faster than the mean flow.

\section{Model results}

Emphasis will be placed on the MM5 21-h forecast that is valid at 2100 UTC 22 June 2004. This particular time is chosen because it is near the halfway point of the flight conducted on 22 June 2004 and because the $\mathrm{CJ}$ is the strongest and the best developed. The model analysis is based on a vertical level of $990 \mathrm{hPa}$, because it is near the level of maximum wind speed and it is

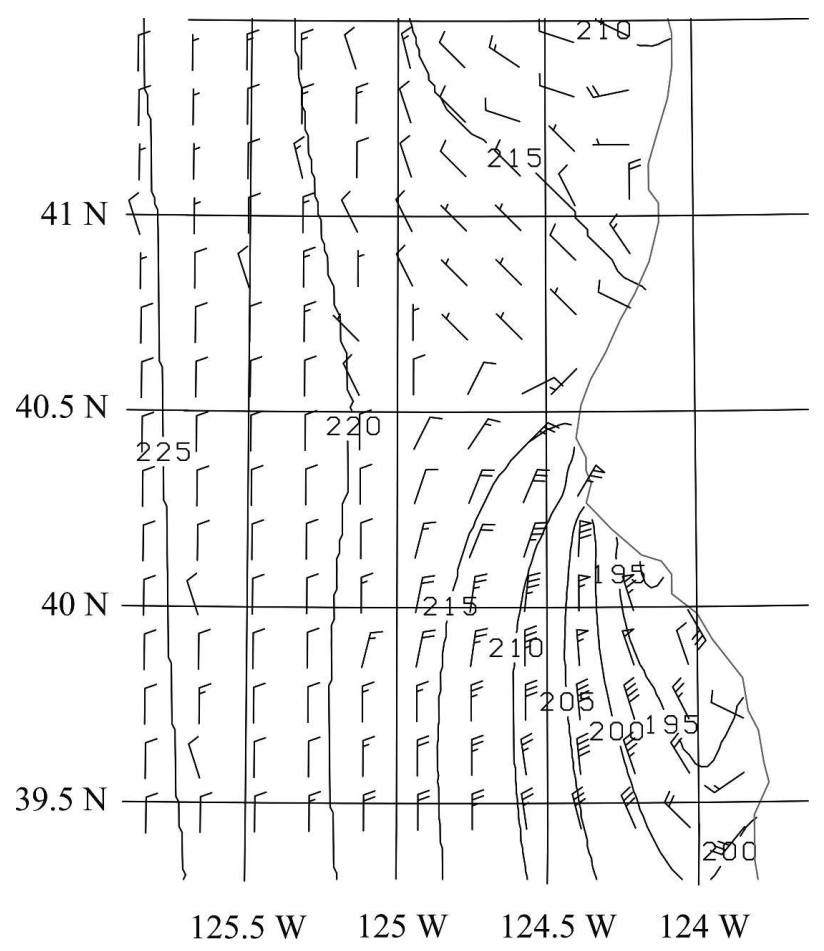

FIG. 12. Geopotential heights $(\mathrm{m})$ and geostrophic wind barbs $\left(\mathrm{m} \mathrm{s}^{-1}\right)$ at $990 \mathrm{hPa}$ from the MM5 21-h forecast valid at $2100 \mathrm{UTC}$ 22 Jun 2004.

centered between the two isobaric surfaces at which the aircraft flew, which were about 986 and $997 \mathrm{hPa}$. When comparing the individual flight legs to the model, the exact isobaric level from the model solution was used.

The full wind from the MM5 simulation is shown in Fig. 11. There is generally a north-northwest direction to the wind and a speed of around $12 \mathrm{~m} \mathrm{~s}^{-1}$ to the north of the cape. To the south of the cape, there is generally a northwest direction to the wind and a maximum wind speed above $20 \mathrm{~m} \mathrm{~s}^{-1}$ in the CJ. Significant acceleration occurs in response to the rapid spatial changes in the PGF. Wind speeds increase by about $8 \mathrm{~m} \mathrm{~s}^{-1}$ over a distance of only about $80 \mathrm{~km}$. The directional change of the wind in the lee of the cape from north to northwest is due to the force imbalance in which the PGF becomes larger than the Coriolis force by a factor of 2 or more. An initial $10 \mathrm{~m} \mathrm{~s}^{-1}$ wind from the north at $43^{\circ} \mathrm{N}$ with a constant $50 \mathrm{~m} \mathrm{~s}^{-1}$ ageostrophic wind from the south would have a final wind velocity of $21 \mathrm{~m} \mathrm{~s}^{-1}$ from $300^{\circ}$ after $1 \mathrm{~h}$, which is comparable to what is simulated by MM5. The wind speed diminishes rapidly to the east of the jet center and much more gradually to the west of the jet center.

Pressure perturbations associated with the Cape Mendocino terrain blocking in MM5 at $990 \mathrm{hPa}$ are very evident in Fig. 12. A similar pattern was inferred 

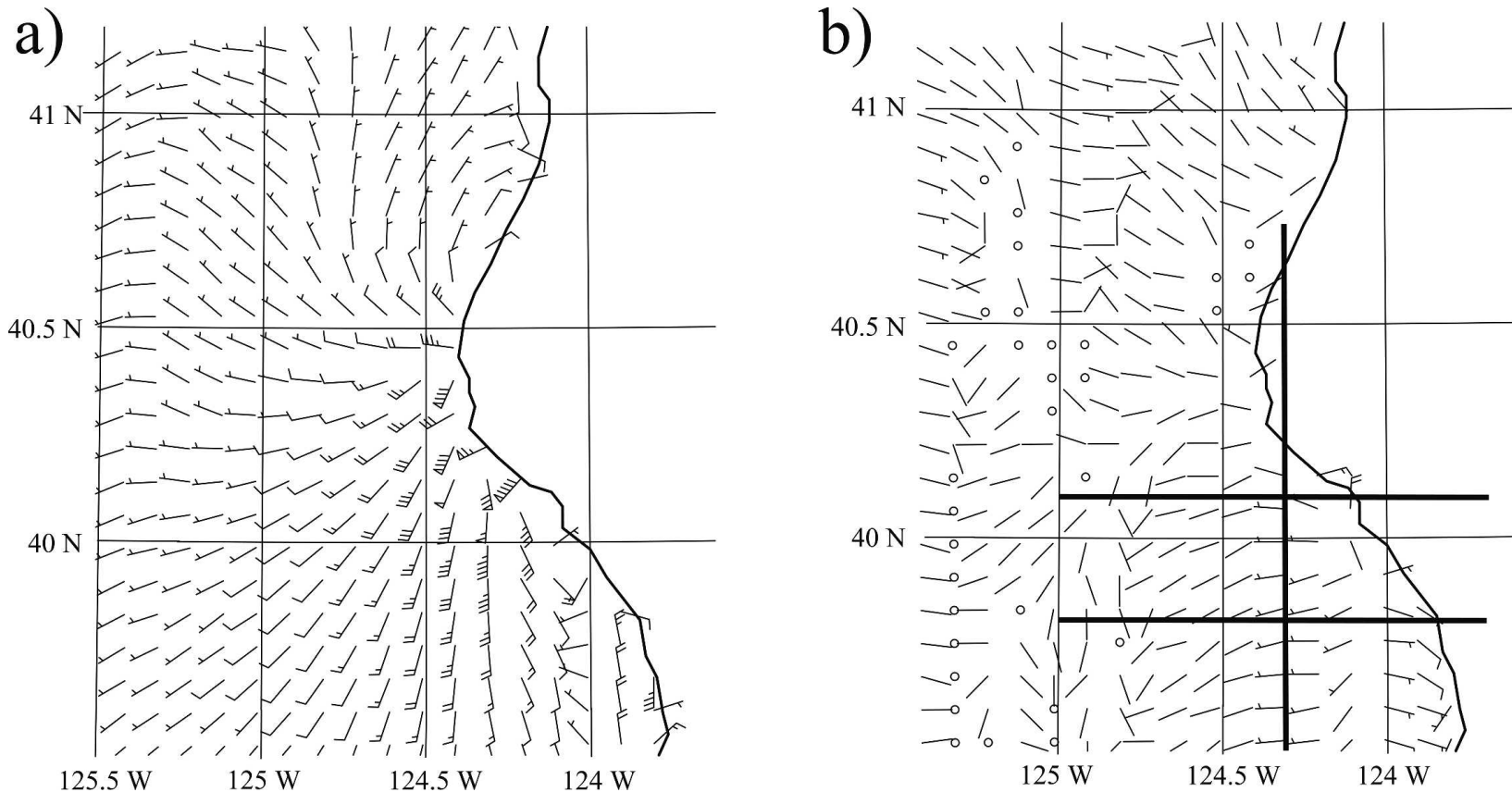

FIG. 13. The 18- and 24-h forecasts valid between 1800 UTC 22 and 0000 UTC 23 Jun 2004 from MM5, showing the 990-hPa (a) average advective wind barbs $\left(\mathrm{m} \mathrm{s}^{-1}\right)$ and $(\mathrm{b})$ isallobaric wind barbs $\left(\mathrm{m} \mathrm{s}^{-1}\right)$. Locations of the cross sections used in Figs. 14 and 15 are shown as dark lines in (b).

by Ström et al. (2001) for their 7 and 12 June 1996 cases. There is a buildup of mass to the north of the cape in response to the low-level mass convergence on the windward side of the cape. Lower geopotential heights are conversely found in the lee of the cape with an enhanced zonal pressure gradient. Weak geostrophic winds are simulated by MM5 offshore to the north of Cape Mendocino. To the south of the cape, the geostrophic wind is very strong and is primarily from the north, with magnitudes in excess of $50 \mathrm{~m} \mathrm{~s}^{-1}$ directly in the lee of the cape. Here the wind speeds of $20 \mathrm{~m} \mathrm{~s}^{-1}$ are extremely subgeostrophic, indicating a large force imbalance. A strong ageostrophic component exists in the MM5 simulation that is comparable to and in places exceeds the actual wind. Geostrophic wind magnitudes decrease gradually to the south, perhaps as a result of adjustment processes. The PGF diminishes rapidly to the east of the CJ until there is only a weak PGF at the coast near Shelter Cove. This collapse of the MABL is similar to that observed by Ström et al. (2001) and Pomeroy and Parish (2001)and to that seen in the modeling work of Tjernström and Grisogono (2000). To the west of the $\mathrm{CJ}$, the pressure gradient decreases. It is thought that such a PGF as simulated by MM5 is forced in large part by the coastal terrain. Results of previous work (e.g., Pomeroy and Parish 2001) suggest that, for strongly forced synoptic situations, the PGF can be very strong within several hundred kilometers of the coast, and the effects of the coastal terrain are of secondary importance in the formation of the CJ.

Large accelerations are present in the lee of the cape as simulated in MM5 and indicate an imbalance in the dynamical forces governing the flow. Figure 11 shows that the acceleration commences near the point of Cape Mendocino and extends to the south-southeast, implying that horizontal mass divergence must be found south of the cape. The lower pressure in this area, as shown in Fig. 12, suggests an enhancement of the PGF and attendant acceleration of the wind.

Ageostrophic components play a very important role in diagnosing the atmospheric motion and may be described as two separate components - the advective wind and the isallobaric wind (first and second term, respectively; Holton 2004):

$$
\mathbf{V}_{a}=\frac{1}{f}\left[\mathbf{k} \times\left(\mathbf{V}_{g} \cdot \boldsymbol{\nabla}\right) \mathbf{V}_{g}+\mathbf{k} \times \frac{\partial \mathbf{V}_{g}}{\partial t}\right] .
$$

The two ageostrophic components at $990 \mathrm{hPa}$ from the MM5 simulations are shown in Figs. 13a,b. The isallobaric components are generally at or below $5 \mathrm{~m} \mathrm{~s}^{-1}$, whereas the advective components are generally much stronger and dominate the total ageostrophic wind. The small isallobaric wind indicates that the pressure gradient is not changing locally in time. Note that the advective component of the ageostrophic wind has a magni- 

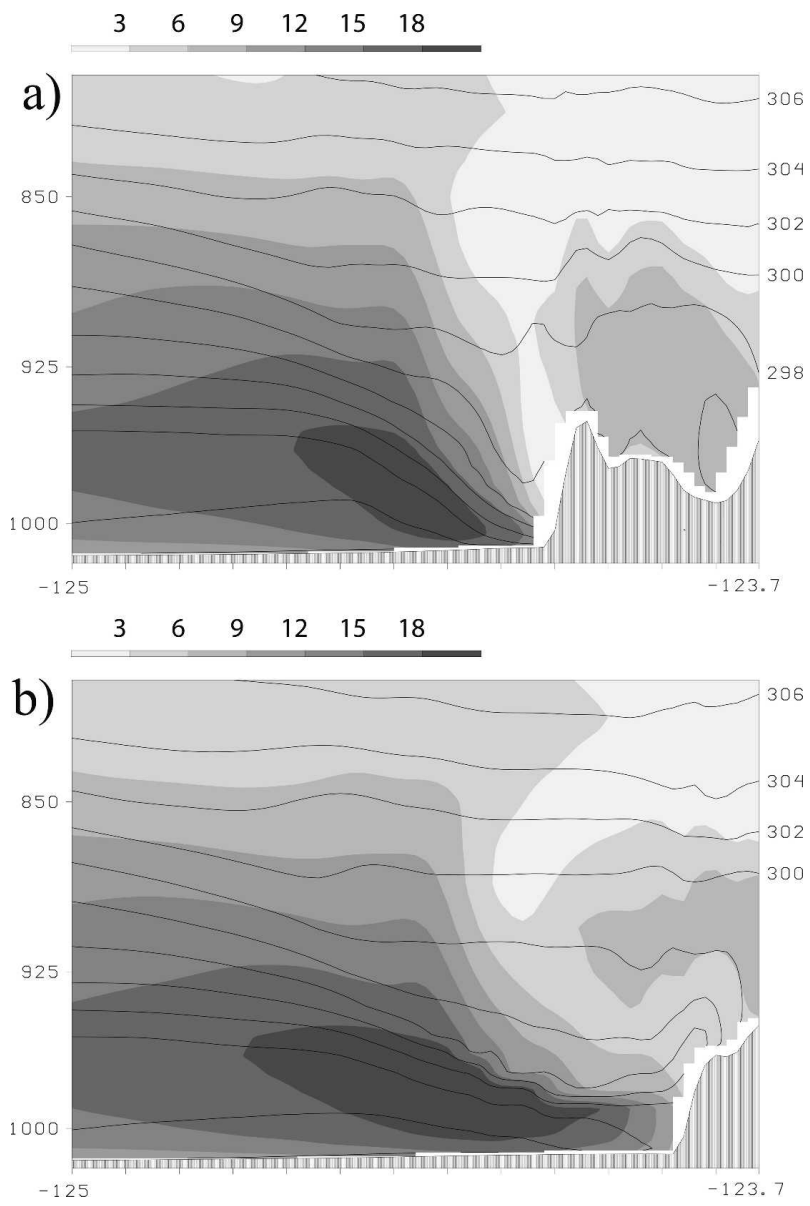

FIG. 14. Cross section of isentropic surfaces (K) and full wind speed grayscale $\left(\mathrm{m} \mathrm{s}^{-1}\right)$ between the surface and $800 \mathrm{hPa}$, from $123.7^{\circ}$ to $125^{\circ} \mathrm{W}$ along (a) $40.1^{\circ}$ and (b) $39.8^{\circ} \mathrm{N}$.

tude near $50 \mathrm{~m} \mathrm{~s}^{-1}$ directly in the lee of the capenearly 3 times as large as the actual wind as simulated in MM5. Ageostrophic components to the south of Cape Mendocino are typically 2 times the magnitude of the actual wind, emphasizing the highly nongeostrophic state of the atmosphere.

Figure 14 shows two cross sections from MM5 at 2100 UTC taken to the south of the cape along the two latitudes where observations were taken. The horizontal locations of the cross sections are shown in Fig. 13b. Maximum winds between 18 and $21 \mathrm{~m} \mathrm{~s}^{-1}$ are seen, with potential temperature surfaces being vertically depressed and tightly packed. This indicates strong subsidence in the area behind the cape, which is due to both the flow over the elevated terrain of Cape Mendocino as well as horizontal spreading within the MABL that is consistent with expansion-fan dynamics (e.g., Winant et al. 1988; Burk and Thompson 1996; Rogers et al. 1998; Haack et al. 2001). The local depres-

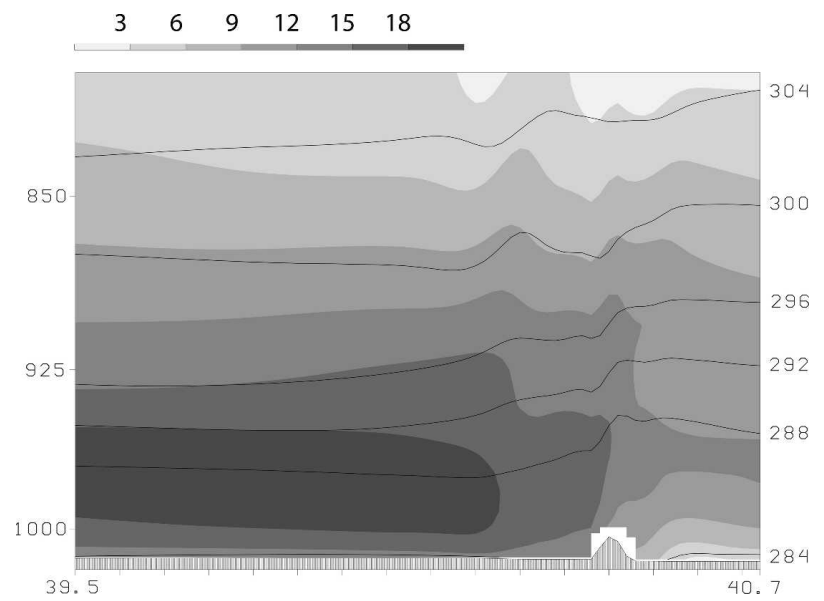

FIG. 15. As in Fig. 14 , but along $124.4^{\circ} \mathrm{W}$ from $39.5^{\circ}$ to $40.7^{\circ} \mathrm{N}$.

sion of the isentropic surfaces in the lee of the cape is also consistent with an enhancement of the PGF. MM5 simulations suggest that there are weak winds above the MABL that are efficiently separated from the strong wind below by the stability at the top of the MABL and that there is more wave activity in the southern cross section.

Figure 15 shows a meridional cross section along $124.4^{\circ} \mathrm{W}$ taken from MM5 at $2100 \mathrm{UTC}$ between $39.5^{\circ}$ and $40.7^{\circ} \mathrm{N}$. The potential temperature surfaces are clearly perturbed over the cape as the flow is forced over the higher terrain with strong localized subsidence $\left(-10 \mathrm{~cm} \mathrm{~s}^{-1}\right)$ just to the south of the cape. Potential temperatures quickly become uniform to the south of the cape. The meridional pressure gradient is near zero south of the collapse of the MABL where the CJ has developed and where the aircraft measurements were taken; only minor meridional variations are simulated after the CJ becomes developed. The maximum wind speed is $18-21 \mathrm{~m} \mathrm{~s}^{-1}$, and, like the potential temperatures, the wind within the $\mathrm{CJ}$ becomes uniform to the south of Cape Mendocino. To the north of the cape, the wind is light because the flow encounters the elevated topography.

\section{Summary and conclusions}

The CJ during the afternoon of 22 June 2004 has several typical and robust features to it. Subsidence associated with the Pacific high caps the MABL. A northerly flow follows the coast and is associated with a weak pressure distribution associated with the Pacific high and the thermal low over the continent. The northerly flow and the MABL are modified by the coastal mountain range along the west coast of North America and locally by Cape Mendocino. 
This particular case of the CJ demonstrates the importance of the local topography of the California coast on the wind and pressure fields. As the northerly wind encounters Cape Mendocino, low-level air is blocked. Convergence results in a high pressure perturbation to the north of the cape. This perturbation is strong because of the stability at the top of the MABL; Froude numbers are less than 1 at low levels to the north of the cape, implying that the air within the MABL is forced primarily around the terrain. From MM5 simulations, a low pressure perturbation forms from the tip of the cape and extends to the south. Pronounced acceleration of the flow is simulated for this case study to the south of Cape Mendocino. MM5 results suggest that the 990$\mathrm{hPa}$ geostrophic wind near the cape is in excess of $70 \mathrm{~m} \mathrm{~s}^{-1}$, with the full wind being only about $12 \mathrm{~m} \mathrm{~s}^{-1}$. Large ageostrophic motion components imply an acceleration of the flow. The resulting horizontal divergence enhances the subsidence in the lee of the cape, which in turn supports the low pressure perturbation and the strong PGF because it depresses the isobaric surface locally. The wind vector increases and shifts to the northwest as the unbalanced flow accelerates to the east across the isobars. This process is consistent with the expansion-fan dynamics that have been discussed by Rogers et al. (1998) and others. MM5 cross sections show that the core of the CJ exists just under the top of the MABL. To the west under the inversion the winds decrease gently, but to the east and above the inversion the winds rapidly diminish. This illustrates just how efficiently the high momentum within the MABL is separated from the low momentum above the MABL and also how the full wind maximum corresponds to the location of the greatest PGF at the top of the MABL.

The in situ data provide direct observation of the structure and forcing of the CJ. The northern legs depict three important regions - the free troposphere, the top portion of the MABL, and the well-mixed area below. To the east, the aircraft is above the MABL, where there is more turbulence and a southerly geostrophic wind as shown by the more variable data and positive slope. To the west, the aircraft penetrates into the top of the MABL, characterized by a strong stability and a geostrophic wind of $67 \mathrm{~m} \mathrm{~s}^{-1}$. This transition into the MABL is confirmed by the measurements of the potential temperature and full wind, which both indicate a strong boundary that separates the two regions at this location. Continuing to the west, the aircraft is below the top portion of the MABL and is in the less stable region below, where the geostrophic wind is almost one-half that of the center $\left(33 \mathrm{~m} \mathrm{~s}^{-1}\right)$. Here, the potential temperature is nearly uniform and the wind gradually diminishes.
There are different synoptic patterns that are typically associated with different CJ structures such as are summarized by Winant et al. (1988). The three typical patterns include a short-lived weak or reversed wind with a weak pressure gradient, a stronger uniform northerly wind with only a small inversion at the top of the MABL, and a strong northerly wind that has strong gradients in wind over short scales along the coast because of the presence of a stronger inversion that interacts strongly with the coastal topography. The CJ on 22 June 2004 is characterized as having weak synoptic forcing so that the cape dominates the local forcing. By contrast, a CJ may occur during strong synoptically forced conditions, such as is described in Pomeroy and Parish (2001). The CJ described in Pomeroy and Parish (2001) was very broad, with wind maxima found from 30 to beyond $100 \mathrm{~km}$ offshore and only a minor influence of the various capes and points, and there was a significantly stronger pressure gradient at the surface. This demonstrates that the CJ may have a broad-scale nature if the synoptic conditions are favorable, and the interaction with the local topography may only perturb this otherwise general pattern and not be the primary mechanism that forms the CJ. The 22 June 2004 CJ is quite the contrary, because the terrain is the primary mechanism for forcing the $\mathrm{CJ}$ and the synoptic forcing is relatively weak. This situation leads to a more localized CJ to the south of the cape instead of a ubiquitous large-scale feature along the coast. Ström et al. (2001) use a momentum budget analysis for two $\mathrm{CJ}$ events to show a significant difference between a mesoscale perturbation-dominated flow and a flow dominated by large-scale forcing. Recognizing the significance of the interactions between the synoptic and local factors in determining the strength and location of the $\mathrm{CJ}$ is important for ultimately diagnosing and forecasting highwind events along the coast.

MM5 results, for the most part, are in good agreement with the UWKA observations and provide evidence of the strongly ageostrophic nature of the CJ environment to the south of Cape Mendocino. There even appears to be agreement between MM5 simulations and observations of the isobaric slopes in the lee of the cape. Measurements of the isobaric surface demonstrate how the PGF changes downstream, adjusting to the imbalance between the wind and mass fields induced by the local topographic forcing.

Acknowledgments. This research was supported in part by the National Science Foundation through Grant ATM-0332202. The authors thank Matt Burkhart, Don Cooksey, and Al Rodi for help with the field measurements and Larry Oolman for assistance with MM5. 


\section{REFERENCES}

Beardsley, R. C., C. E. Dorman, C. A. Friehe, L. K. Rosenfield, and C. D. Wyant, 1987: Local atmospheric forcing during the Coastal Ocean Dynamics Experiment 1: A description of the marine boundary layer and atmospheric conditions over a northern California upwelling region. J. Geophys. Res., 92, $1467-1488$.

Bridger, A. F. C., W. C. Brick, and P. F. Lester, 1993: The structure of the marine inversion layer off the central California coast: Mesoscale conditions. Mon. Wea. Rev., 121, 335-351.

Burk, S. D., and W. T. Thompson, 1996: The summertime lowlevel jet and marine boundary layer structure along the California coast. Mon. Wea. Rev., 124, 668-686.

Chao, S. Y., 1985: Coastal jets in the lower atmosphere. J. Phys. Oceanogr., 15, 361-371.

Dorman, C. E., T. Holt, D. P. Rodgers, and K. Edwards, 2000: Large-scale structure of the June-July 1996 marine boundary layer along California and Oregon. Mon. Wea. Rev., 128, $1632-1652$.

Edwards, K. A., A. M. Rogerson, C. D. Winant, and D. P. Rogers, 2001: Adjustment of the marine atmospheric boundary layer to a coastal cape. J. Atmos. Sci., 58, 1511-1528.

Grell, G. A., J. Dudhia, and D. R. Stauffer, 1994: A description of the fifth-generation Penn State/NCAR Mesoscale Model (MM5). NCAR Tech. Note NCAR/TN-398+STR, 122 pp.

Haack, T., S. D. Burk, C. Dorman, and D. Rogers, 2001: Supercritical flow interaction within the Cape Blanco-Cape Mendocino orographic complex. Mon. Wea. Rev., 129, 688-708.

Holton, J. R., 2004: An Introduction to Dynamic Meteorology. 4th ed. Elsevier, 529 pp.

Parish, T. R., 2000: Forcing of the summertime low-level jet along the California coast. J. Appl. Meteor., 39, 2421-2433.

— , A. R. Rodi, and R. D. Clark, 1988: A case study of the summertime Great Plains low level jet. Mon. Wea. Rev., 116, 94-105.

- M. D. Burkhart, and A. R. Rodi, 2007: Determination of the horizontal pressure gradient force using global positioning system onboard an instrumented aircraft. J. Atmos. Oceanic Technol., 24, 521-528.

Pomeroy, K. R., and T. R. Parish, 2001: A case study of the interaction of the summertime coastal jet with the California topography. Mon. Wea. Rev., 129, 530-539.

Rodi, A. R., and T. R. Parish, 1988: Aircraft measurement of mesoscale pressure gradients and ageostrophic winds. J. Atmos. Oceanic Technol., 5, 91-101.

Rogers, D. P., and Coauthors, 1998: Highlights of Coastal Waves 1996. Bull. Amer. Meteor. Soc., 79, 1307-1326.

Shapiro, M. A., and P. J. Kennedy, 1982: Airborne radar altimeter measurements of geostrophic and ageostrophic winds over irregular terrain. J. Appl. Meteor., 21, 1739-1746.

Ström, L., M. Tjernström, and D. P. Rogers, 2001: Observed dynamics of coastal flow at Cape Mendocino during Coastal Waves 1996. J. Atmos. Sci., 58, 953-977.

Tjernström, M., 1999: The sensitivity of supercritical atmospheric boundary-layer flow along a coastal mountain barrier. Tellus, 51A, 880-901.

—, and B. Grisogono, 2000: Simulations of supercritical flow around points and capes in a coastal atmosphere. J. Atmos. Sci., 57, 108-135.

Winant, C. D., C. E. Dorman, C. A. Friehe, and R. C. Beardsley, 1988: The marine layer off northern California: An example of supercritical channel flow. J. Atmos. Sci., 45, 3588-3605.

Zemba, J., and C. A. Friehe, 1987: The marine boundary layer jet in the coastal ocean dynamics experiment. J. Geophys. Res., 92, 1489-1496. 